\title{
Correction of uncomplicated cases of transposition of the great arteries
}

\author{
Eoin Aberdeen \\ From The Hospital for Sick Children, Great Ormond Street, London W.C.I
}

In recent years the surgical treatment of transposed great arteries has become one of the standard operations of cardiac surgery. Though exchange of the great arteries has theoretical attractions, the success of rearrangement of the atrial flow has been so great that this will probably remain the operation of choice for some time yet. The principle of this operation was first described by Albert (1955). Although Senning (1959) was the first to achieve success with this operative approach, its widespread application did not occur until Mustard described his technique in 1964. Other modifications of the principle had been attempted by Creech et al. (1958), Merendino et al. (1957), Shumacker (196I), and Barnard, Shrire, and Beck (1962), but only Barnard's case had been successful.

Our experience has been with the Mustard operation. Since February I965 II2 cases have had Mustard's operation at The Hospital for Sick Children, Great Ormond Street. The types of cases are shown in Table I. Seventyeight anatomically uncomplicated cases form the largest group and discussion will be limited to these.

\section{Results}

Of the 78 simple cases, 10 (13\%) died in hospital. The reasons for the deaths are shown in Table 2. The important conclusion is that almost all the causes of death were avoidable. Late deaths have occurred in 7 cases in the entire group of Mustard's operations (II2 cases), but only the last two were in cases of simple transposition of the great arteries, the first five also having ventricular septal defects. However, these delayed deaths do emphasize the danger of arrhythmias (especially atrial flutter) and heart block (Table 3).

\section{Post-operative arrhythmias}

The conduction in the first days and weeks after operation is shown in Table 4. The cases are divided into roughly half. In the first 54
TABLE I Mustard's operations, February 1965 to May 1970

\begin{tabular}{|c|}
\hline $\begin{array}{l}\text { Transposition of great arteries (simple) } \\
\text { Transposition of great arteries + ventricular } \\
\text { septal defect } \\
\text { Transposition of great arteries + ventricular } \\
\text { septal defect + pulmonary artery unbanding } \\
\text { Transposition of great arteries + ventricular } \\
\text { septal defect + pulmonary stenosis } \\
\text { Transposition of great arteries (complex) }\end{array}$ \\
\hline \\
\hline
\end{tabular}

TABLE 2 Simple transposition of great arteries: cause of death in hospital in 10 cases

\begin{tabular}{|c|c|}
\hline Case No & Cause of death \\
\hline $\begin{array}{r}9 \\
30\end{array}$ & $\begin{array}{l}\text { Superior vena caval obstruction } \\
\text { Pulmonary oedema }\end{array}$ \\
\hline 33 & Persistent ductus arteriosus tear \\
\hline 42 & $\begin{array}{l}\text { ? Induced ventricular fibrillation for long } \\
\text { period }\end{array}$ \\
\hline 44 & $\begin{array}{l}\text { ? Induced ventricular fibrillation for long } \\
\text { period }\end{array}$ \\
\hline $\begin{array}{l}60 \\
61 \\
68\end{array}$ & $\begin{array}{l}\text { Post-operative haemorrhage } \\
\text { Pulmonary vascular disease }\left(R_{p} / R_{s}=I \cdot 2 / I\right) \\
\text { Dacron patch leak }\end{array}$ \\
\hline 70 & Low output state \\
\hline III & Pulmonary vascular disease $\left(R_{p} / R_{s}=2 / 3\right)$ \\
\hline
\end{tabular}

TABLE 3 Mustard's operations: late deaths in 7 cases

\begin{tabular}{lll}
\hline Age (yr.) & \multicolumn{1}{c}{ Cause of death } & $\begin{array}{c}\text { Interval between } \\
\text { operation and } \\
\text { death (mth.) }\end{array}$ \\
\hline 5 & Atrial flutter & 6 \\
4 & Nodal/atrial flutter & 23 \\
I-10/12 & 3rd degree AV block (late onset) & 30 \\
4 & 3rd degree AV block & 32 \\
2 & Measles bronchopneumonia & I I \\
I $^{\star}$ & Febrile convulsions; & I I \\
I6 & inhalation pneumonia & 7 wk. \\
\hline
\end{tabular}

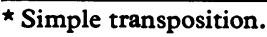

cases the incidence of conduction troubles was much greater than subsequently. At this time some minor modifications to Mustard's operation were made in an attempt to reduce the arrhythmias. It can be seen that sinus 
TABLE 4 Mustard's operations: early post-operative rhythm

\begin{tabular}{llc}
\hline Rhythm & Cases I-54 & Cases 55-112 \\
\hline Sinus & 17 & 40 \\
Nodal & 20 & 2 \\
2nd degree AV block & I & 3 \\
Complete AV dissociation & $7(5 \mathrm{~s})^{\star}$ & I0 (5 s) \\
Atrial flutter & 5 & I (briefly) \\
\hline
\end{tabular}

« $\mathrm{s}=$ later sinus rhythm.

TABLE 5 Mustard's operations: long term atrial flutter

\begin{tabular}{lll}
\hline & Cases I-54 & Cases 55-112 \\
\hline $\begin{array}{l}\text { Post-operative atrial flutter } \\
\text { (long term) }\end{array}$ & I4 & Nil \\
I (briefly)
\end{tabular}

TABLE 6 Mustard's operations: variations in technique

\begin{tabular}{cl}
\hline Case No. & \multicolumn{1}{c}{ Variations } \\
\hline 2 & $\begin{array}{l}\text { Atrial septum used as pedicle flap } \\
\text { Superior vena cava cannula to right side } \\
\text { Atrial pedicle flap posterior to coronary } \\
\text { sinus }\end{array}$ \\
23,30 & $\begin{array}{l}\text { Prolonged artificial ventricular fibrillation } \\
\text { abandoned }\end{array}$ \\
47 & $\begin{array}{l}\text { Interrupted sutures over atrial conduction } \\
\text { paths }\end{array}$ \\
65 & $\begin{array}{l}\text { Coronary sinus not cut back } \\
\text { Dacron only used for dividing atria }\end{array}$ \\
66 & $\begin{array}{l}\text { Suture line posterior to coronary sinus } \\
\text { Pericardium and Dacron used for dividing } \\
\text { atria }\end{array}$ \\
\hline
\end{tabular}

rhythm occurred much more frequently in the latter part of the series and nodal rhythm much less commonly. Complete AV dissociation has occurred in a number of cases where sutures have not been placed near the main AV conduction bundle or the AV node, and in a number of these the conduction has later returned to sinus rhythm (see Table 4).

Over a longer term atrial flutter developed in a large proportion of the early part of the series, but since further attempts have been made to avoid damage to either the sinus or the AV nodes or to the interatrial conduction pathways the incidence of atrial flutter has been almost abolished (Table 5).

The modifications made to the operation have been almost all designed to reduce the incidence of arrhythmias and are listed in Table 6. The superior vena cava cannula is now placed as far as possible from the sinus node, and when a suture line crosses the presumed position of the interatrial conduction pathways interrupted sutures are used. To avoid damage to the posterior internodal pathway the coronary sinus is no longer cut back, and since Case 66 the patch has been placed

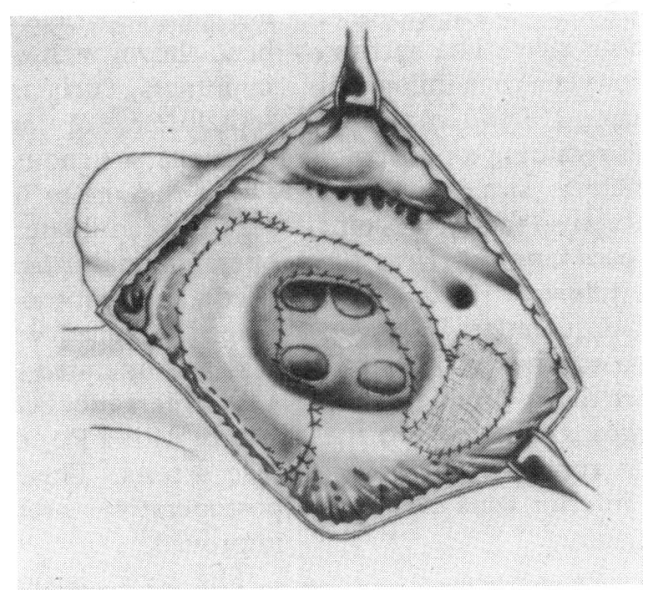

FIG. I Diagram showing completed operation. The pericardial patch surrounds the pulmonary veins, and the ' $D$ ' shaped patch of Dacron lies over the inferior vena caval orifice.

well posterior to the coronary sinus allowing this to drain to the pulmonary atrium, but the effect of this is not significant as a cause of systemic desaturation.

The type of operation which has been used in the last 43 cases is shown in Fig. I. An attempt was made to use Dacron for the whole interatrial division, but this proved unsuccessful in two of three cases, so the technique used thereafter was to employ pericardium for most of the patch except where a narrow strip of Dacron was required - that is, over the inferior vena caval inflow. (In those cases which we have seen at necropsy some time after operation the pericardium

FIG. 2 Comparison of hospital death with age at operation.

TRANSPOSITION OF THE GREAT ARTERIES. SIMPLE: 78 CASES

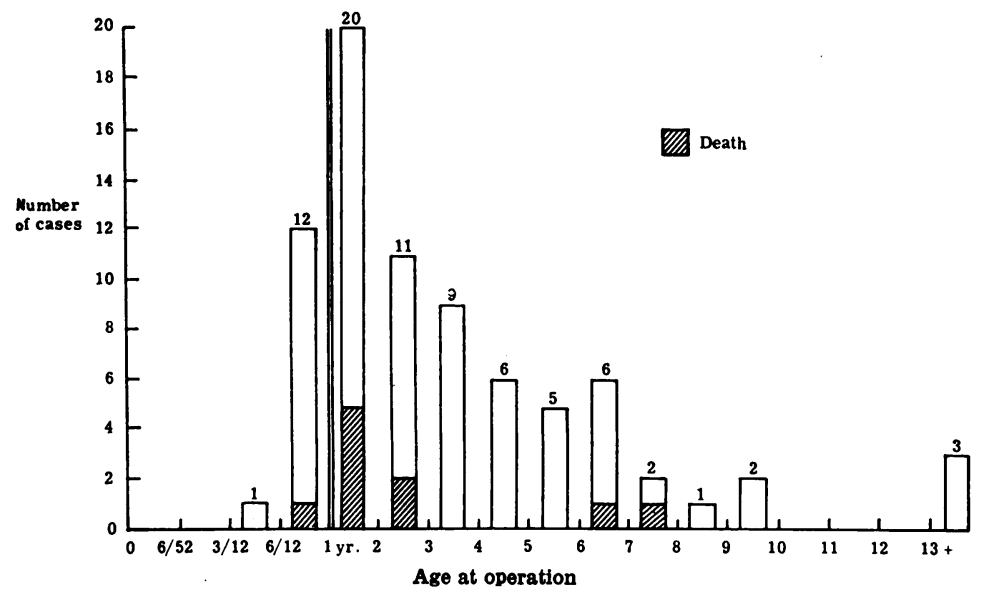


appeared to have contracted to one-third or one-quarter of its previous size.) The narrowest portion of the inferior vena cava inflow has therefore been made using Dacron cut to the shape of a ' $D$ ', and also retaining a portion of the atrial septum which is sutured to the straight edge of the Dacron so that at no point does the pericardium pass completely across the inferior vena caval inflow.

Superior vena caval obstruction is known to have occurred in two surviving cases after operation, but in neither did it produce signs of any note as the azygos vein accepted the full flow, and thus the superior vena caval flow was routed to the inferior vena cava and back to the systemic atrium.

\section{Optimum age at operation}

Effective palliation by the creation of an atrial septal defect has made an immense difference to the natural history of transposition of the great arteries. Whereas 85 per cent of cases were dead by six months of age, the highest mortality being in the uncomplicated cases, now the uncomplicated cases appear to have about a ro per cent risk if the Rashkind balloon septostomy is made in the early weeks of life (Rashkind and Miller, I966). There would also seem to be about a ro per cent risk of death in the next year or so after the septostomy. In addition it has been appreciated that there is quite a high risk of cerebral infarction. One of our cases which died II months after Mustard's operation (performed when the child was I year old) died with persistent febrile convulsions and inhalation pneumonia. He had been thought to have had a relatively minor stroke as an infant, but post-mortem examination showed a large area of brain scarring.

There is therefore some urgency about performing correction for transposition of the great arteries. If one simply considered the mortality risk it would be reasonable to perform Mustard's operation at six months of age if the mortality rate were no more than Io per cent greater than the rate if the operation were performed at about 2 years of age. In the past three years we have been operating on children at a progressively younger age. Our experience so far suggests that, as has been shown with other open-heart operations in infants, such as correction of ventricular septal defect or correction of total anomalous pulmonary venous drainage, an infant between the age of 6 and 12 months is a good surgical candidate (Fig. 2). Among 13 cases operated on during infancy there has been one death, and that was possibly the result of prolonged induced ventricular fibrillation. One case was operated on at 3 months of age as a semi-emergency because the child was in severe failure with a $\mathrm{PO}_{2}$ of 25 and had had two cardiac arrests. This child required prolonged postoperative intensive care but eventually improved.

The series is not yet large enough to be dogmatic, but it seems that, given a good background of intensive care for infants, especially intensive respiratory care, the elective age for performing Mustard's operation in uncomplicated cases of transposition of the great arteries is probably in infancy, and perhaps at about six months of age.

\section{References}

Albert, H. M. (1955). Surgical correction of transposition of the great vessels. Surgical Forum, $5,74$.

Barnard, C. N., Shrire, V., and Beck, W. (I962). Complete transposition of the great vessels. A successful complete correction. Fournal of Thoracic and Cardiovascular Surgery, 43, 768.

Creech, O., Jr., Mahaffey, D. E., Sayegh, S. F., and Sailors, E. L. (1958). Complete transposition of the great vessels: a technique for intracardiac correction. Surgery, 43, 349.

Merendino, K. A., Jesseph, J. E., Herron, P. W., Thomas, G. I., and Vetto, R. R. (1957). Interatrial venous transposition. A one-stage intracardiac operation for the conversion of complete transposition of the aorta and pulmonary artery to corrected transposition: theory and clinical experience. Surgery, 42, 898.

Mustard, W. T. (1964). Successful two-stage correction of transposition of the great vessels. Surgery, $55,469$.

Rashkind, W. J., and Miller, W. W. (1966). Creation of an atrial septal defect without thoracotomy. A palliative approach to complete transposition of the great arteries. Fournal of the American Medical Association, 196, 991.

Senning, A. (1959). Surgical correction of transposition of the great vessels. Surgery, 45, 966.

Shumacker, H. B., Jr. (I96I). A new operation for transposition of the great vessels. Surgery, 50, 773. 